Article

\title{
Azospirillum brasilense Enhances Recycling of Fish Effluent to Support Growth of Tomato Seedlings
}

\section{Jonathan S. Mangmang *, Rosalind Deaker and Gordon Rogers}

Faculty of Agriculture and Environment, The University of Sydney, Central Avenue, Eveleigh, NSW 2015, Australia; E-Mails: rosalind.deaker@sydney.edu.au (R.D.); gordon.rogers@sydney.edu.au (G.R.)

* Author to whom correspondence should be addressed; E-Mail: jsm_yan@yahoo.com; Tel.: +61-45-222-9155.

Academic Editors: Douglas D. Archbold and Stefania de Pascale

Received: 26 March 2015 / Accepted: 1 June 2015 / Published: 5 June 2015

\begin{abstract}
Increasing environmental concerns and growing demand for safer and sustainable food production presents significant challenges for agricultural production. One potential technique, which could help improve crop productivity without adverse impact on the environment, is the use of beneficial microbes in crop production systems. This study evaluated the effects of three Azospirillum brasilense strains on tomato seedlings fertilized with effluent from freshwater fish aquaculture. Seeds were inoculated with A. brasilense strains Sp7, Sp7-S and Sp245 before sowing and after transplanting. Seedlings were raised under controlled greenhouse conditions with natural light. Inoculated seedlings produced longer roots (67\%), bigger leaves $(22 \%)$, higher seedling biomass (>33\%), and greater protein $(15 \%)$ and endogenous plant IAA (94\%) contents. Inoculation with Sp7 and Sp245 increased the number of leaves and stem diameter by 8 and 10\%, respectively. Seedling height was also increased by inoculation, but only with Sp7. In addition, seedlings inoculated with strains Sp7-S and Sp245 had higher total phosphorus content, while inoculation with Sp245 increased the activity of the enzyme peroxidase, which suggests that plant defense responses had been triggered. The result demonstrates the potential of the applied $A$. brasilense strains to enhance the usefulness of fish effluent as fertilizer for tomato seedling production.
\end{abstract}


Keywords: Azospirillum brasilense; fish effluent; PGPR; recycling; seedling; sustainable; vegetable

\section{Introduction}

Recycling nutrients from organic sources and modifying farming practices towards sustainable agriculture have gained attention in recent years. Motivating factors include the cost of fuel that drives agricultural production, and the increasing public awareness for health and environmental issues. Limiting the use of chemical inputs while improving productivity and reducing ecological impact are among the guiding principles for sustainable food production systems. One potential source of organic fertilizer is the wastewater or fish effluent from freshwater aquaculture. This nutrient-rich effluent has been used successfully to fertigate cultivated crops and hydroponic vegetables $[1,2]$. However, some studies reported that plants fertilized solely with fish wastewater, particularly in a system called aquaponics, showed mineral deficiency symptoms, which could be due to either inadequate nutrient availability or inability to recover nutrients efficiently [3,4]. In this regard, the use of beneficial microbes has been considered one possible safe, efficient and practical agent to enhance plant growth [5]. One group of beneficial microbes is referred to as plant growth-promoting rhizobacteria (PGPR). They can act as biostimulants through phytohormone production, mineral solubilization, improving nutrient uptake efficiencies, and increasing tolerance to stresses [6]. Phytostimulatory effects mainly include stimulation of root morphological development, which could facilitate efficient absorption of water and nutrients leading to improved plant growth [7]. One of the most studied plant-associative genera of PGPR is Azospirillum [8]. Inoculation with Azospirillum spp. has been demonstrated to improve plant growth and yield via improving mineral and water uptake of colonized roots [9]. While the mechanisms by which Azospirillum promote plant growth are not clear, it has been proposed to include phytohormone production, biological nitrogen fixation, solubilization of nutrients, and enhancement of water and nutrient uptake [10].

Azospirillum spp. are a widespread colonizer which have been isolated in the rhizosphere of a wide variety of plant species, primarily cereals and grasses [11,12]. For instance, A. brasilense $\mathrm{Sp} 7$ was first isolated from the rhizosphere of Digitaria decumbens and was found to colonize the root surface of a number of crop plants [13]. Strain Sp7-S, a spontaneous mutant of Sp7, was found-in contrast to the Sp7 wild type - to colonize wheat roots between cortical cells and crevices around the emergence of lateral roots [14]. Another important strain of A. brasilense is Sp245, which has been isolated from surface-disinfected roots of a Brazilian wheat cultivar [15]. This strain had a higher colonizing potential compared to other strains, and colonization spread in the intercellular spaces (apoplast) of the root cortex [16]. This PGPR has the potential to be a promising inoculant as natural or biofertilizer for agricultural exploitation due to numerous beneficial effects [17]. Azospirillum inoculation was reported to increase plant dry weight, stem diameter, leaf number, plant height, density and length of roots and fine root hairs, and yield of some cereal crops (see review [10]). While Azospirillum-plant association has been widely explored, only a few studies have been done with vegetables. To date, no investigations have determined the effects of $A$. brasilense inoculation on tomato seedlings where 
fish effluent was used as fertilizer. In this study, three strains of A. brasilense (i.e., Sp7, Sp7-S and Sp245) were evaluated for their impact on tomato seedlings fertilized with fish effluent.

\section{Materials and Methods}

\subsection{Seed and Inoculum Preparation, and Inoculation}

Tomato (Lycopersicon esculentum L. cv. Grosse Lisse) seeds were initially washed with Millipore water prior to surface sterilization. Seeds were treated with $1 \%(\mathrm{v} / \mathrm{v})$ sodium hypochlorite $(\mathrm{NaClO})$ for $4 \mathrm{~min}$ followed by $70 \%(\mathrm{v} / \mathrm{v})$ ethanol for $1 \mathrm{~min}$. The surface-sterilized seeds were washed with autoclaved Millipore water to remove residual bleach and ethanol. Seeds were then spread out in sterile Petri dishes with dry autoclaved filter paper prior to inoculation. The inocula of Azospirillum brasilense Sp7, Sp7-S, and Sp245 were provided by Dr. Rosalind Deaker, University of Sydney. Inoculum of each strain was taken from pure cultures stored with glycerol in $-80{ }^{\circ} \mathrm{C}$ freezer and streaked onto the nutrient agar containing 15,5 and $3 \mathrm{~g} / \mathrm{L}$ of agar, peptone and beef extract, respectively, in water, and incubated at $28{ }^{\circ} \mathrm{C}$ for 2 days. A loopful of each culture was transferred separately into the nutrient broth containing 10 and $6 \mathrm{~g} / \mathrm{L}$ of peptone and beef extract, respectively, in water, and incubated for 3 days at $28{ }^{\circ} \mathrm{C}$ with constant agitation. The number of colony forming units (CFU) was determined after serial dilution and plating on nitrogen-free broth (NFB) agar with congo red [18]. Bacterial cultures were pelleted by centrifugation $(4000 \times \mathrm{g}, 5 \mathrm{~min})$, washed twice with autoclaved $30 \mathrm{mM} \mathrm{MgSO}_{4}$, and resuspended in the same solution. The production of IAA in the culture supernatant of $A$. brasilense strains was also determined using a spectrophotometer at $535 \mathrm{~nm}$ following the method described by Patten and Glick [19].

Seeds were inoculated at an average population of $\log 9.6 \mathrm{CFU} / \mathrm{mL}$ by soaking the surface-sterilized seeds in the prepared bacterial cell suspension at a volume of $200 \mu \mathrm{l}$ per seed for $1 \mathrm{~h}$ with constant agitation at room temperature to allow bacteria to bind to the seed coat and for seed imbibition. Non-inoculated seed was treated with autoclaved $30 \mathrm{mM} \mathrm{MgSO}_{4}$. Re-inoculation was done by drenching seedlings with $1 \mathrm{~mL} /$ seedling of bacterial cell suspension immediately after thinning.

\subsection{Growing Condition and Treatments}

All the materials and inputs used, except fish effluent, were sterilized by either autoclaving or treating with $80 \%$ (v/v) ethanol (except seeds) and $1 \% \mathrm{NaClO}$. The experiment was conducted in the glasshouse facility at the University of Sydney. Control and inoculated seeds were pre-germinated for 2-3 days using Petri dishes with moistened autoclaved filter paper at $24{ }^{\circ} \mathrm{C}$ inside the growth cabinet with a $12 \mathrm{~h}$ light/12 $\mathrm{h}$ dark cycle. Seedlings were transferred at the rate of 1-2 seedlings/cell into sterilized plastic seedling trays filled with moistened, autoclaved perlite/vermiculite (1/1, v/v). Seedling trays were arranged in a randomized complete block design with 8 replications in a growth room at $26 \pm 4{ }^{\circ} \mathrm{C}$ with natural light. After 7-10 days from sowing, seedlings were thinned, leaving only one healthy seedling per cell. The supply of fish effluent was started immediately after thinning at a rate of $30 \mathrm{~mL} / \mathrm{seedling} / \mathrm{day}$. The effluent was sourced from a fish tank stocked with silver perch (Bidyanus bidyanus M.) fed 3 times a week to satiation with a native fish pellet diet containing $35 \%$ protein. Analysis of the fish effluent was done weekly for determination of $\mathrm{NO}_{3}{ }^{-}, \mathrm{PO}_{4}{ }^{3-}, \mathrm{Ca}^{2+}, \mathrm{Fe}$, 
and $\mathrm{pH}$ using a complete and comprehensive test kit for fresh and marine water (Rolf C. Hagen Inc., Mansfield, MA, USA; http://cahagen-en.com/).

\subsection{Measurements and Analyses}

Seedlings were harvested 35 days after sowing (DAS) and washed for the determination of the number of leaves, stem diameter $(\mathrm{mm})$, seedling height $(\mathrm{cm})$, root length $(\mathrm{cm})$, and fresh and dry weight of both roots and shoots (g). All measurements were taken from 10 randomly-selected seedlings per replication. Leaf area was measured using a portable leaf area meter (LI-3100C, LI-COR Inc., Lincoln, NE, USA). Roots were scanned using a dedicated Desk Scan II scanner (Expression 700, Epson, Nagano, Japan). Scanned root images were analyzed by WinRhizo Pro V. 2007c (Regent Instruments Inc., Quebec, Canada) for total root length measurement. Roots and shoots were oven dried for 3 days at $70{ }^{\circ} \mathrm{C}$ for total $\mathrm{N}$ and $\mathrm{P}$ determination using a CNS Vario max analyzer (Elementar Analysensysteme GmBH, Hanau, Germany) and a colorimetric technique [20], respectively. Roots of randomly selected inoculated plants in each treatment were excised using a sterile scalpel. Roots including those substrates loosely adhering to the roots were included during crushing with the addition of $1 \mathrm{~mL}$ peptone phosphate buffer. An aliquot of the suspension was plated after a series of dilutions on a special type of NFB agar medium with congo red [18]. After 4 days of incubation at $28{ }^{\circ} \mathrm{C}$, the number of CFUs with the distinctive color morphology of the test strain were counted and expressed per gram of root fresh weight [21]. The data were analyzed following analysis of variance (ANOVA) using Genstat ${ }^{\circledR}$ 14th edition software (VSN International, Hemel Hempstead, UK). Mean differences were determined using Fisher's protected least significant difference (LSD) $(p<0.05)$.

\subsection{IAA Quantification}

The endogenous level of plant IAA was quantified following the method described by Ribaudo et al. [22] with slight modifications. Approximately $1 \mathrm{~g}$ of frozen plant sample was homogenized with liquid nitrogen using a mortar and pestle. The resulting powder was dissolved in methanol/water $(4 / 1, \mathrm{v} / \mathrm{v})$ with polyvinylpyrrolidone and incubated overnight at $4{ }^{\circ} \mathrm{C}$. The extract was cleared by centrifugation $(10,000 \times \mathrm{g} 10 \mathrm{~min})$, and the solid residue was re-extracted. The two extracts were combined and concentrated using a speed vacuum evaporator (UNIVAPO $100 \mathrm{ECH}$, Montreal Biotech. Inc., Montreal, Canada) until the volume was reduced to one-tenth of the initial volume. The $\mathrm{pH}$ of the concentrated sample was adjusted to 2.5-3.0 and partitioned twice with $1 \%$ acetic acid in ethyl acetate $(\mathrm{v} / \mathrm{v})$. The acidic ethyl acetate extract was completely dried using a speed vacuum evaporator. The dried sample was dissolved in acetic acid/methanol/water $(1 / 10 / 89, v / v / v)$ and filtered. The plant extract and IAA standard were resolved on a reversed phase $\mathrm{C}_{18}$ column with a quad pump HPLC system (Agilent Tech. Inc., Santa Clara, CA, USA). A solvent gradient program was optimized for IAA detection in the presence of $1 \%$ acetic acid. The eluent profile was traced by a dual monitoring system with diode array and fluorescence detectors. The chromatogram was analyzed using LC/MS Agilent chemstation software. 


\subsection{Peroxidase Activity}

Peroxidase activity was assayed colorimetrically following the method of Ben-Shalom et al. [23] with slight modifications. Approximately $0.5 \mathrm{~g}$ of frozen plant sample was ground with liquid nitrogen in a mortar and pestle. The resulting powder was suspended in $50 \mathrm{mM}$ sodium phosphate buffer with $\mathrm{pH} 6.5$ and incubated for $2 \mathrm{~h}$ at $4{ }^{\circ} \mathrm{C}$. The mixture was then centrifuged $(4000 \times \mathrm{g}, 25 \mathrm{~min})$ at $4{ }^{\circ} \mathrm{C}$ and the supernatant was saved. The protein content was determined in comparison with a bovine serum albumin (BSA) protein standard. Peroxidase activity was determined by adding $100 \mathrm{mM}$ pyrogallol to the crude plant extract containing $10-40 \mu \mathrm{g}$ protein. An aliquot of $90 \mathrm{mM}$ hydrogen peroxide $\left(\mathrm{H}_{2} \mathrm{O}_{2}\right)$ was added last to initiate the reaction. Absorbance at $300 \mathrm{~nm}$ was recorded every min starting from $\mathrm{H}_{2} \mathrm{O}_{2}$ addition up to $6 \mathrm{~min}$. Measurements was performed in triplicate and the diluted protein extract

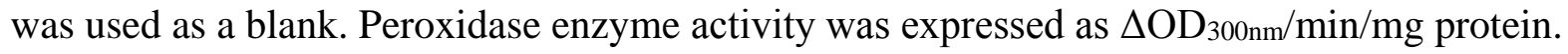

\section{Results and Discussion}

This study evaluated the impact of Azospirillum brasilense inoculation on the performance of tomato seedling grown in soilless culture with fish effluent as fertilizer. In this study, only data with significant results are presented in the succeeding table and figures. The average population of the strains recovered at the end of the experiment was $7.9 \mathrm{log} \mathrm{CFU} / \mathrm{g}$ of root fresh weight. While there might be variation in the numbers compared to their average initial inoculated populations, this suggests that $A$. brasilense can colonize the roots of tomato seedlings under soilless culture. The variation in numbers could be attributed to competition with existing indigenous microorganisms in the fish effluent. In wheat, Shelud'ko et al. [24] observed that the reduction in the Azospirilla number in the seedling roots might be due to the migration of some adsorbed cells into the growing medium. The average amount of IAA produced by strains was $5.9 \mu \mathrm{g} / \mathrm{mL}$, which is typical among Azospirillum species. This capacity can be enhanced with the addition of the auxin precursor L-tryptophan [25].

On the other hand, the fish effluent contained an average of $20,5,20$ and $0 \mathrm{mg} / \mathrm{L}$ of $\mathrm{NO}_{3}{ }^{-}, \mathrm{PO}_{4}{ }^{3-}$, $\mathrm{Ca}^{2+}$ and $\mathrm{Fe}$, respectively, with a neutral $\mathrm{pH}$ throughout the duration of the experiment. These elemental concentrations are relatively low compared to those in conventional hydroponics [26]. This is likely because the fish tank was not intensively stocked with fish, so less soluble metabolic wastes had accumulated. Nevertheless, it supported seedling growth without major nutrient deficiencies. It may be that a constant supply of fish effluent, even with low nutrient levels, can prevent depletion of nutrients in the root zone. Supporting this, Tyson et al. [4] observed that frequent flushing of the media, even with a lower $\mathrm{N}$ concentration solution, could replenish $\mathrm{N}$, and there would be no appreciable depletion of the nutrient in the root zone. This could also be relevant to all other nutrients. For instance in conventional hydroponics, it was previously proposed by Olsen [27] that plant nutrients in the system are absorbed at a constant rate regardless of concentration, provided that (1) the nutrient solution is thoroughly mixed and in constant contact with the roots, and (2) the proportion and concentration of nutrients in solution remains constant. 


\subsection{Effects on Seedling Growth}

Seedlings inoculated with strains Sp7 and Sp245 were significantly taller with bigger stems and more developed leaves compared to non-inoculated plants (Table 1). The only exception was the height of the seedlings inoculated with the latter strain, which was comparable with the non-inoculated ones. Biomass production was also significantly enhanced by inoculation with Sp7. These results correspond with the findings of Bashan et al. [28] who reported that inoculation of tomato with A. brasilense $\mathrm{Cd}$ increased stem circumference, number of leaves and seedling dry weight. These are the most common measurable effects on plant growth following A. brasilense inoculation. In maize, Gholami and Nezarat [29] reported that inoculation with Azospirillum and other PGPR strains resulted in early seedling emergence and development. A similar result was also documented in spring wheat, in which $A$. brasilense improved several growth parameters including germination, seedling development, and dry weight of roots and shoots, flowering, and yield [25,30]. In this study, the leaf area and root length increased due to inoculation with all strains by up to $22 \%$ and $67 \%$ over controls, respectively (Table 1, Figure 1). In addition, fresh and dry seedling biomass also increased in response to Azospirillum inoculation by $33 \%$ and $47 \%$ over controls, respectively. These results conform with those by Hadas and Okon [31], who found significant increases in root dry weight (50\%), aboveground dry weight $(90 \%)$, leaf surface area $(90 \%)$, and root length $(35 \%)$ of tomato plants inoculated with $A$. brasilense Cd. In maize, inoculation with Azospirillum strains increased leaf surface area of maize under sterile and non-sterile conditions by $78 \%$ and $65 \%$, respectively, relative to noninoculated controls [29]. The enhancement of tomato seedling root and shoot growth in the current study could be related to the activity of the bacteria through production of growth regulators that alter root morphology leading to improved water and nutrient absorption [32]. Vikram et al. [33] reported that auxin produced by PGPR can influence plant growth, particularly root development, which is often linked to better absorption of essential nutrients and water. It has long been hypothesized that IAA production by Azospirillum plays a major role in plant growth promotion through enhancing root growth characteristics [10]. The results also indicate the competitive ability of the strains to survive and colonize, and affect the growth and development of tomato plants, despite the existence of indigenous microflora in the fish effluent [34].

Table 1. Effect of inoculation with three A. brasilense strains on the growth of 35-day old tomato seedlings fertilized with fish effluent.

\begin{tabular}{lccccccc}
\hline $\begin{array}{l}\text { A. brasilense } \\
\text { Strains }\end{array}$ & $\begin{array}{c}\text { Leaf } \\
\text { Number }\end{array}$ & $\begin{array}{c}\text { Plant Height } \\
(\mathbf{c m})\end{array}$ & $\begin{array}{c}\text { Stem Diameter } \\
(\mathbf{m m})\end{array}$ & $\begin{array}{c}\text { Leaf Area } \\
\left(\mathbf{c m}^{\mathbf{2}} / \text { Plant }\right)\end{array}$ & $\begin{array}{c}\text { Root Length } \\
(\mathbf{c m})\end{array}$ & $\begin{array}{c}\text { Fresh Weight } \\
(\mathbf{g} / \text { Plant })\end{array}$ & $\begin{array}{c}\text { Dry Weight } \\
(\mathbf{m g} / \text { Plant) }\end{array}$ \\
\hline Control & $3.07^{\mathbf{c}}$ & $11.43^{\mathbf{b}}$ & $1.78^{\mathbf{b}}$ & $24.12^{\mathbf{c}}$ & $60^{\mathbf{b}}$ & $0.50^{\mathbf{c}}$ & $36^{\mathbf{c}}$ \\
\hline Sp7 & $3.34^{\mathbf{a}}$ & $12.75^{\mathbf{a}}$ & $2.04^{\mathbf{a}}$ & $28.05^{\mathbf{b}}$ & $100^{\mathbf{a}}$ & $0.76^{\mathbf{a}}$ & $64^{\mathbf{a}}$ \\
\hline Sp7-S & $3.15^{\mathbf{b}, \mathbf{c}}$ & $12.07^{\mathbf{b}}$ & $1.80^{\mathbf{b}}$ & $29.88^{\mathbf{a}, \mathbf{b}}$ & $97^{\mathbf{a}}$ & $0.59^{\mathbf{b}}$ & $48^{\mathbf{b}}$ \\
\hline Sp245 & $3.29^{\mathbf{a}, \mathbf{b}}$ & $11.57^{\mathbf{b}}$ & $1.86^{\mathbf{b}}$ & $30.31^{\mathbf{a}}$ & $104^{\mathbf{a}}$ & $0.65^{\mathbf{b}}$ & $47^{\mathbf{b}}$ \\
\hline LSD (5\%) & $0.14^{\mathbf{b}}$ & $0.65^{3}$ & 0.13 & 1.99 & 12 & 0.09 & 8 \\
\hline
\end{tabular}

Control, no inoculation; Means in a column with the same superscript letters are not significantly different by LSD at $p \leq 0.05$. 


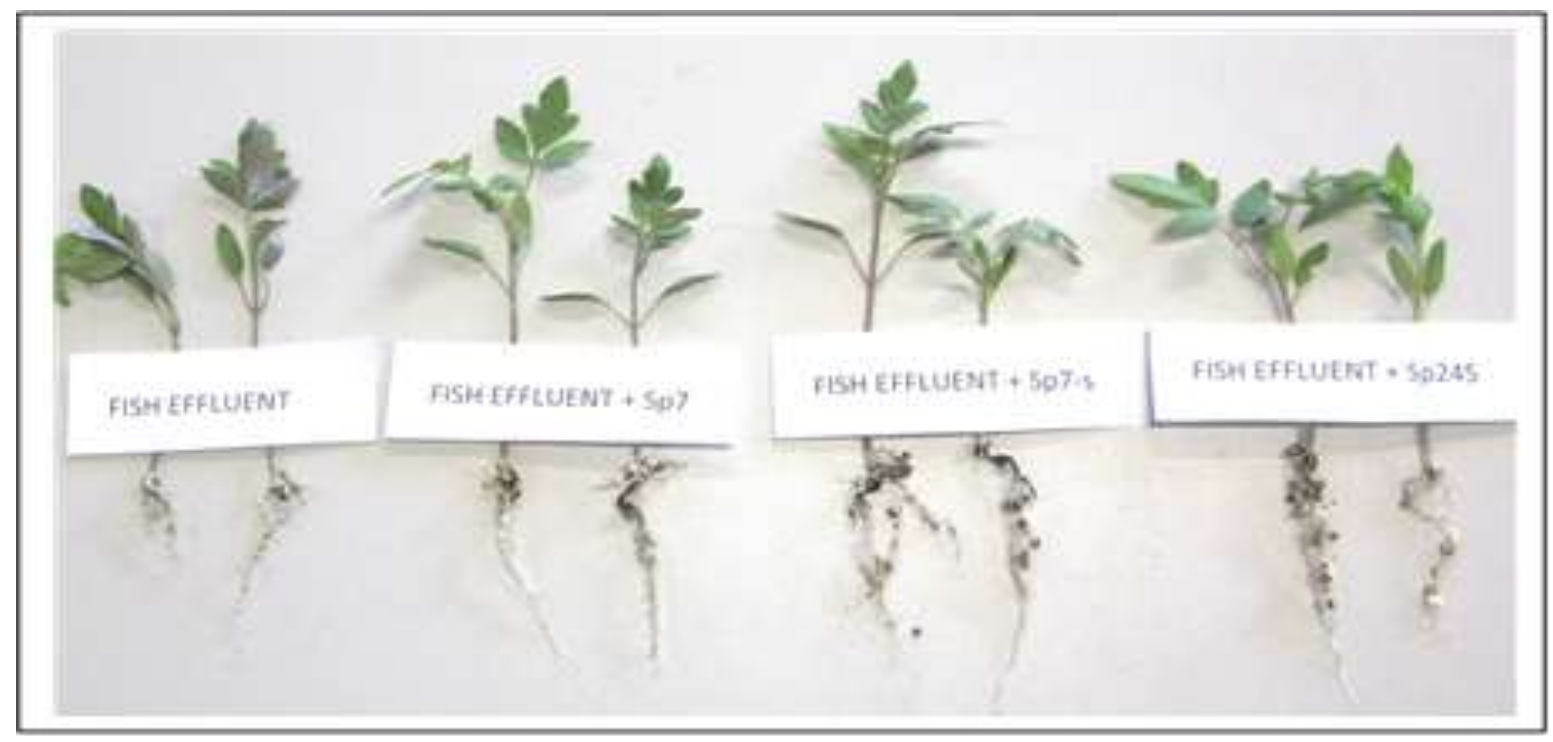

Figure 1. Photo of 35-day old tomato seedlings not inoculated (control) or inoculated with one of three strains of Azospirillum brasilense (Sp7, Sp7-S and Sp245) and fertilized with fish effluent. Note denser and longer root systems of inoculated seedlings than non-inoculated ones

\subsection{Effects on Metabolic Activities}

The effect of inoculation on the level of endogenous plant IAA is presented in Figure 2. Inoculated seedlings had a significantly higher IAA content than non-inoculated seedlings. The increase in IAA concentration due to inoculation with Sp245, Sp7-S and Sp7 was more than 10, 70 and 100\%, respectively, over controls. The activity of $A$. brasilense and its intrinsic IAA production could account for the effects on root and shoot growth. Their interaction with seedling roots, at the biochemical and molecular levels (e.g., secretion and exudation of growth substances), might also have altered some of the plant signaling pathways that resulted in the production of plant hormones by the host plant [35]. This rising level of hormonal activity could have an important implication on the overall plant physiology [22]. Inoculation also promoted the accumulation of protein level in plants (Figure 3). Inoculated seedlings had up to $60 \%$ more protein than control plants. This result was also documented with wheat, in which $A$. brasilense-inoculated plants had a higher protein concentration, particularly when supplied with increasing $\mathrm{N}$ [36]. In this study, there was no significant difference observed among $\mathrm{N}$ content (data not presented) of inoculated and control plants despite the enhancement of growth. However, seedlings inoculated with strains Sp7-S and Sp245 had a higher total phosphorus (P) content, by 20 and 12\%, respectively, over non-inoculated seedlings (Figure 4). The most plausible explanation for increased mineral content of inoculated plants with A. brasilense is due to additive effects of an improved root system that enable plants to absorb nutrient and water efficiently [37]. Increased $\mathrm{P}$ uptake due to A. brasilense inoculation was also observed in barley, sorghum, and rice, particularly at the flowering stage [38]. The influence of A. brasilense inoculation on peroxidase activity showed variable results (Figure 5). This is probably because Azospirillum spp. are not a typical biocontrol agent, and many of the strains lack the direct suppressive chemicals that can affect plant pathogens [10]. Most attempts at biological control of Azospirillum in previous studies showed indirect 
effects, and there has been no explicit evidence for direct biocontrol mechanisms used by the bacteria [8]. Nevertheless, this study demonstrates that there was a two-fold increase of peroxidase activity due to Sp245, which could have an important implication for biotic and abiotic responses. This type of plant response may have been triggered by Sp245 because it has the highest endophytic colonization ability of roots. In addition, Savitsky et al. [39] reported that some plant peroxidases are able to catalyze IAA oxidation [39]. Thus, the lower quantities of endogenous plant IAA found in the seedlings inoculated with Sp245 compared to the other strains might be due to the increased activity of peroxidase. Pereyra et al. [40] also found that the increase of peroxidase activity detected during Rhizobium nodulation of Medicago truncatula was related to the control of auxin level in the roots.

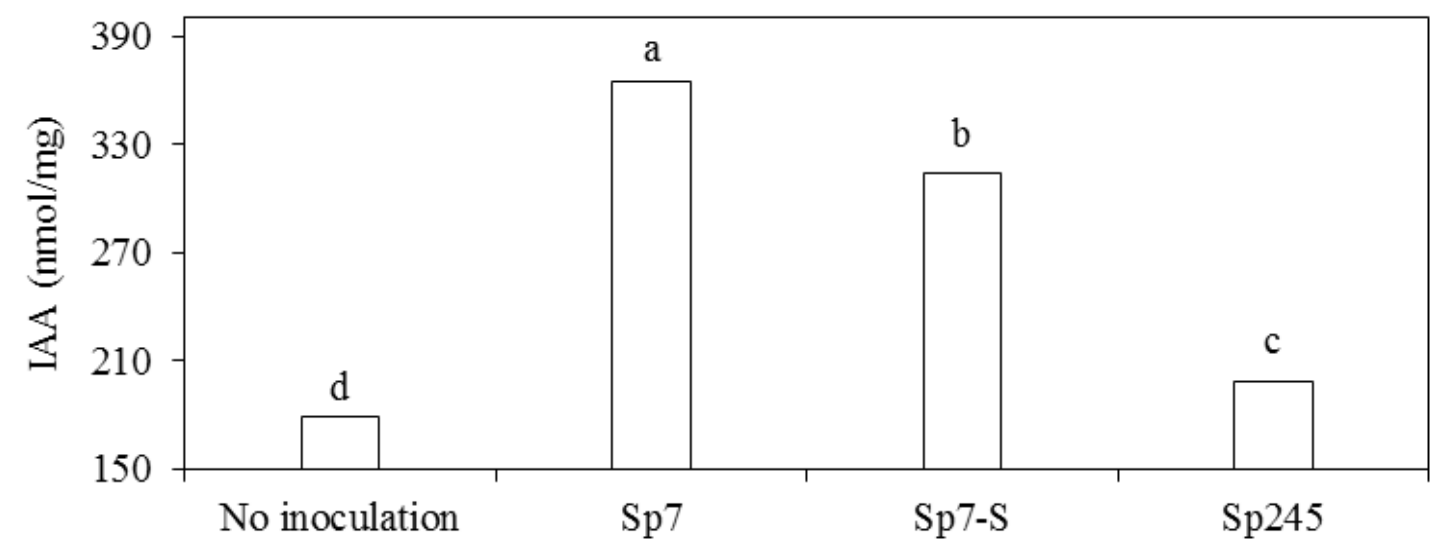

Figure 2. Endogenous plant IAA content of 35-day old non-inoculated (control) and A. brasilense-inoculated tomato seedlings fertilized with fish effluent. Different letters indicate significant differences by LSD at $p<0.05$. Sp7, Sp7-S, and Sp245 were the strains of Azospirillum brasilense used to inoculate seedlings.

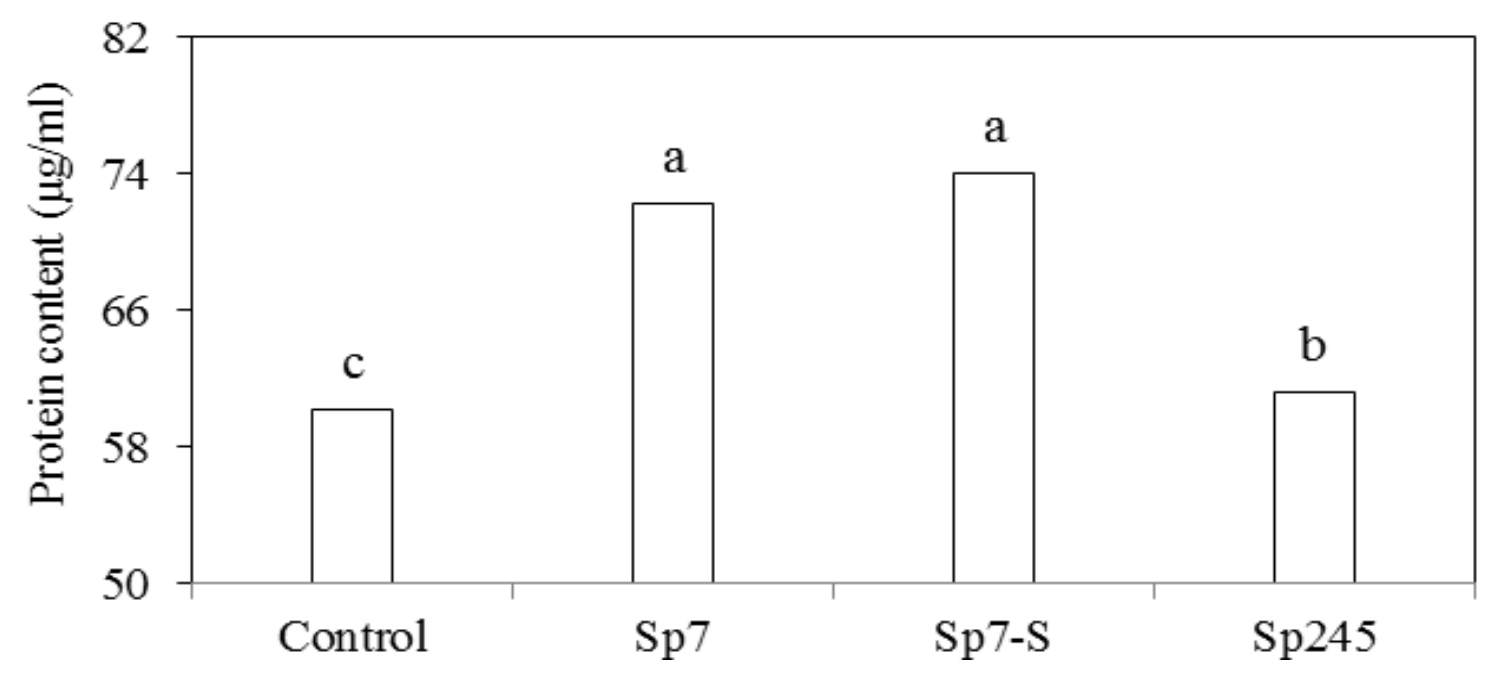

Figure 3. Protein content of 35-day old non-inoculated (control) and A. brasilense-inoculated tomato seedlings fertilized with fish effluent. Different letters indicate significant differences by LSD at $p<0.05$. Sp7, Sp7-S and Sp245 were the strains of A. brasilense used to inoculate seedlings. 


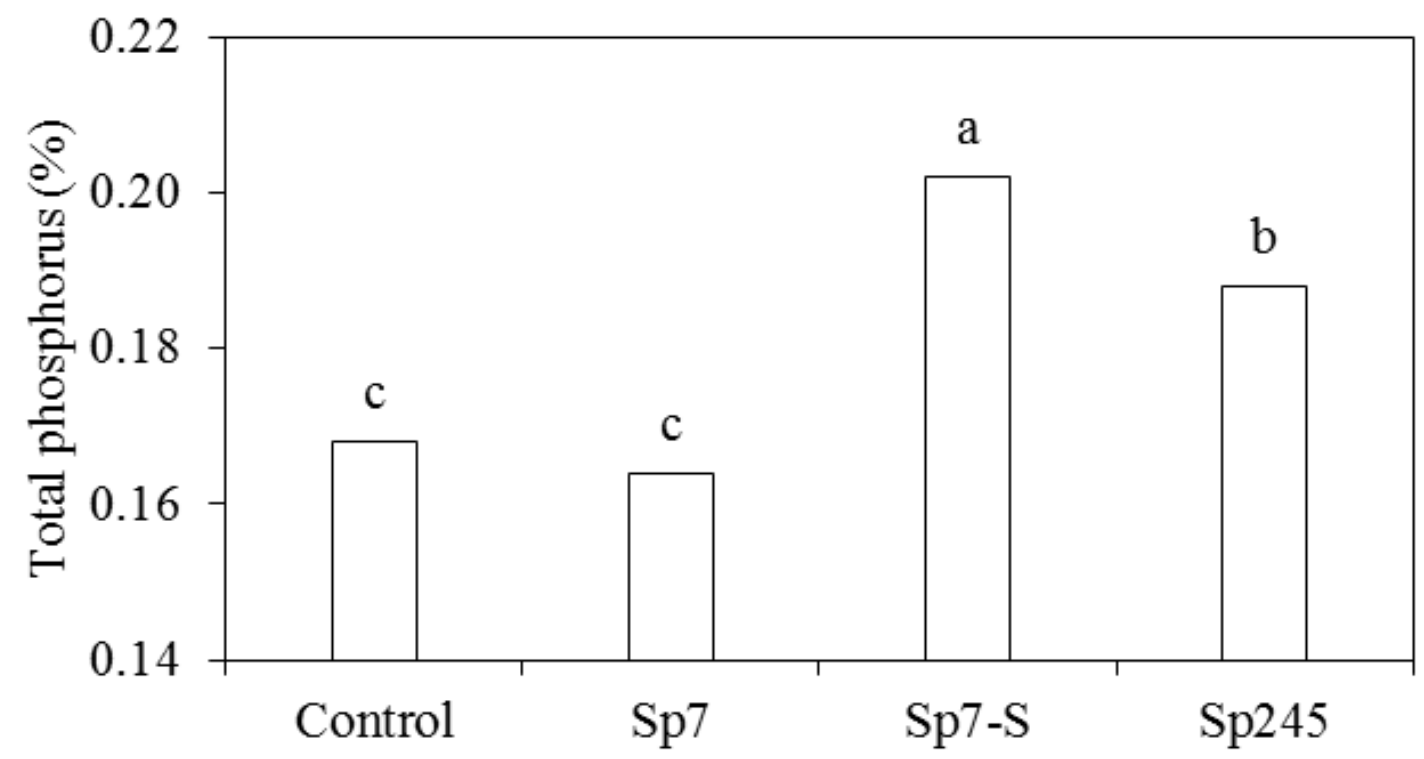

Figure 4. Total phosphorus content of 35-day old non-inoculated (control) and A. brasilense-inoculated tomato seedlings fertilized with fish effluent. Different letters indicate significant differences by LSD at $p<0.05 . \mathrm{Sp} 7, \mathrm{Sp} 7-\mathrm{S}$ and $\mathrm{Sp} 245$ were the strains of A. brasilense used to inoculate seedlings.

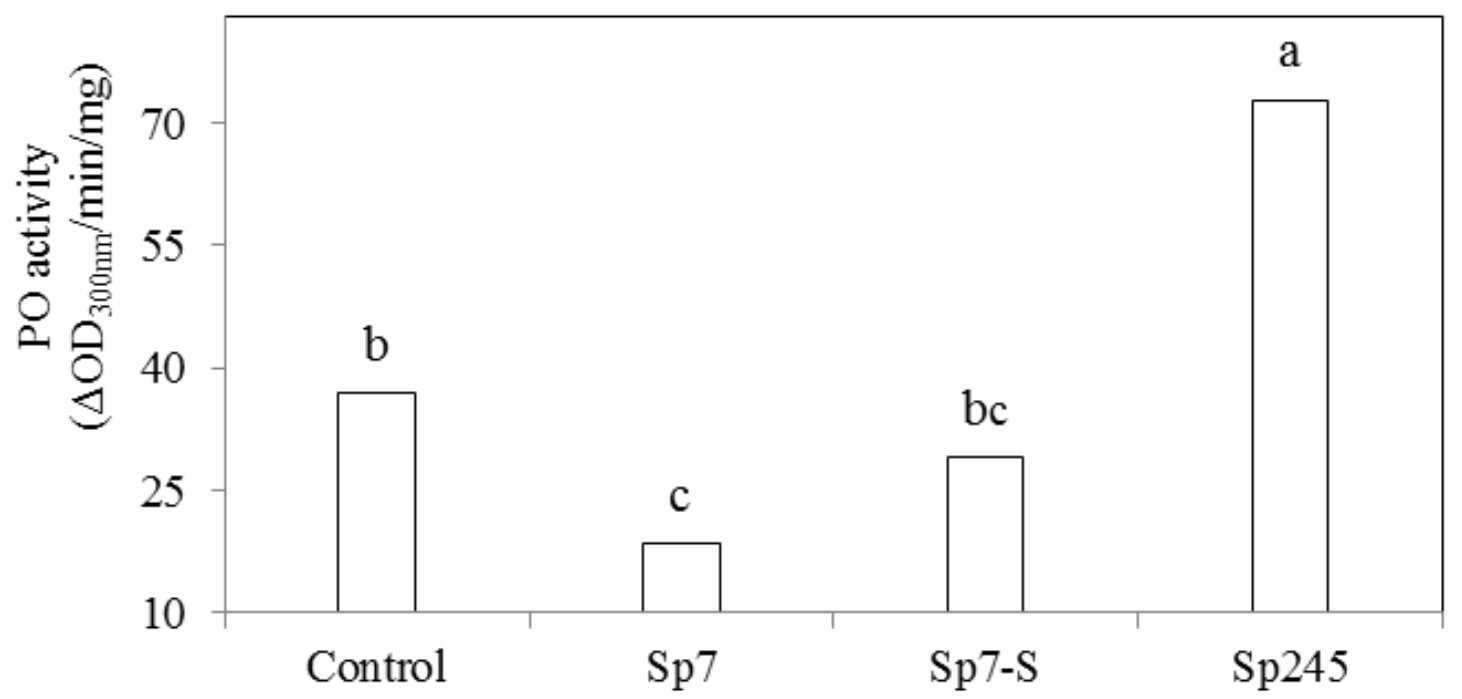

Figure 5. Peroxidase activity (PO) of 35-day old non-inoculated (control) and A. brasilense-inoculated tomato seedlings fertilized with fish effluent. Different letters indicate significant differences by LSD at $p<0.05$. Sp7, Sp7-S and Sp245 were the strains of Azospirillum brasilense used to inoculate seedlings.

\section{Conclusions}

Inoculation of tomato seedlings with the A. brasilense strains Sp7, Sp7-S and Sp245 demonstrated improvement of growth and development during 35 days of growth while fertigated with fish effluent. Inoculation increased total protein, total $\mathrm{P}$ and endogenous plant IAA content. Strain Sp245 also stimulated peroxidase activity, which could be indicative of activation of the plant defense system. 
In addition, the different strains survived and showed substantial colonization activity in the roots of the tomato seedlings despite the presence of existing microflora in the fish effluent. Hence, the strains have shown the potential to be a practical agent to aid vegetable seedling establishment and, more importantly, to enhance the usefulness of fish effluent as fertilizer for plant production. However, more studies need to be done to test the response of other vegetable crops to inoculation with A. brasilense strains, and to determine if other promising PGPR have potential as bioinoculants for sustainable agriculture applications.

\section{Acknowledgement}

The first author wishes to thank the Australian Center for International Agricultural Research (ACIAR) for the John Allwright Fellowship. The authors are grateful to Dr. Joy Becker for providing the fish effluent, and Applied Horticultural Research (AHR) for the transport and other logistical support.

\section{Author Contributions}

This work was a product of the combined effort of all of the authors. All authors conceptualized and designed the study. Jonathan Mangmang performed the experiments, gathered and analyzed the data, and wrote the manuscript with assistance from all other authors. Rosalind Deaker and Gordon Rogers provided technical advice and assistance during the conduct of the study, and revised and improved the manuscript.

\section{Conflict of interest}

The authors declare no conflict of interest.

\section{References}

1. Rakocy, J.E.; Bailey, D.S.; Shultz, R.C.; Danaher, J.J. Preliminary evaluation of organic waste from two aquaculture systems as a source of inorganic nutrients for hydroponics. Acta Hort. 2007, 742, 201-208.

2. Nichols, M.; Savidov, N. Aquaponics: A nutrient and water efficient production system. Acta Hort. 2011, 947, 129-132.

3. Graber, A.; Junge, R. Aquaponic systems: Nutrient recycling from fish wastewater by vegetable production. Desalination 2009, 246, 147-156.

4. Tyson, R.V.; Treadwell, D.D.; Simonne, E.H. Opportunities and challenges to sustainability in aquaponic systems. Horttechnology 2011, 21, 6-13.

5. Dubrovsky, J.G.; Puente, M.E.; Bashan, Y. Arabidopsis thaliana as a model system for the study of the effect of inoculation by azospirillum brasilense sp245 on root hair growth. Soil Biol. Biochem. 1994, 26, 1657-1664.

6. Saharan, B.; Nehra, V. Plant growth promoting rhizobacteria: A critical review. Life Sci. 2011, 21, 1-30.

7. Okon, Y.; Labandera-Gonzalez, C.A. Agronomic applications of Azospirillum: An evaluation of 20 years worldwide field inoculation. Soil Biol. Biochem. 1994, 26, 1591-1601. 
8. Bashan, Y.; Holguin, G. Azospirillum-Plant relationships: Environmental and physiological advances (1990-1996). Can. J. Microbiol. 1997, 43, 103-121.

9. Okon, Y. Azospirillum as a potential inoculant for agriculture. Trend. Biotechnol. 1985, 3, 223-228.

10. Bashan, Y.; de-Bashan, L.E. How the plant growth-promoting bacterium Azospirillum promotes plant growth: A critical assessment. Adv. Agro. 2010, 108, 77-136.

11. Gafny, R.; Okon, Y.; Kapulnik, Y.; Fischer, M. Adsorption of Azospirillum brasilense to corn roots. Soil Biol. Biochem. 1986, 18, 69-75.

12. Jain, D.K.; Patriquin, D.G. Root hair deformation, bacterial attachment, and plant growth in wheat-Azospirillum associations. Appl. Environ. Microbiol. 1984, 48, 1208-1213.

13. Arsène, F.; Katupitiya, S.; Kennedy, I.R.; Elmerich, C. Use of LacZ-fusions to study the expression of nif genes of Azospirillum brasilense in association with plants. MPMI-Mol. Plant Microb. Interact. 1994, 7, 748-757.

14. Kennedy, I.R.; Tchan, Y.-T. Biological nitrogen fixation in non-leguminous field crops: Recent advances. In Biological Nitrogen Fixation for Sustainable Agriculture; Springer: Amsterdam, the Netherlands, 1992; pp. 93-118.

15. Baldani, V.L.D.; Alvarez, M.A.B.; Baldani, J.; Döbereiner, J. Establishment of inoculated Azospirillum spp. in the rhizosphere and in roots of field grown wheat and sorghum. Plant Soil 1986, 90, 35-46.

16. Schloter, M.; Hartmann, A. Endophytic and surface colonization of wheat roots (Triticum aestivum) by different Azospirillum brasilense strains studied with strain-specific monoclonal antibodies. Symbiosis 1998, 25, 159-179.

17. Vessey, J.K. Plant growth promoting rhizobacteria as biofertilizers. Plant Soil 2003, 255, 571-586.

18. Bashan, Y.; Holguin, G.; Lifshitz, R. Isolation and characterization of plant growth-promoting rhizobacteria. In Methods in Plant Molecular Biology and Biotechnology, Glick, B.R., Thompson, J.E., Eds.; CRC Press: Boca Raton, FL, USA, 1993; pp. 331-345.

19. Patten, C.L.; Glick, B.R. Role of Pseudomonas putida indoleacetic acid in development of the host plant root system. Appl. Environ. Microbiol. 2002, 68, 3795-3801.

20. Jones, J.B., Jr. Laboratory Guide for Conducting Soil Tests and Plant Analysis; CRC Press: Boca Raton, FL, USA, 2001.

21. Gamalero, E.; Berta, G.; Massa, N.; Glick, B.R.; Lingua, G. Synergistic interactions between the ACC deaminase-producing bacterium Pseudomonas putida UW4 and the AM fungus Gigaspora rosea positively affect cucumber plant growth. FEMS Microbiol. Ecol. 2008, 64, 459-467.

22. Ribaudo, C.; Krumpholz, E.; Cassán, F.; Bottini, R.; Cantore, M.; Curá, J. Azospirillum sp. promotes root hair development in tomato plants through a mechanism that involves ethylene. J. Plant Growth Regulat. 2006, 25, 175-185.

23. Ben-Shalom, N.; Ardi, R.; Pinto, R.; Aki, C.; Fallik, E. Controlling gray mould caused by Botrytis cinerea in cucumber plants by means of chitosan. Crop. Protect. 2003, 22, 285-290.

24. Shelud'Ko, A.V.; Shirokov, A.A.; Sokolova, M.K.; Sokolov, O.I.; Petrova, L.P.; Matora, L.Y.; Katsy, E.I. Wheat root colonization by Azospirillum brasilense strains with different motility. Microbiology 2010, 79, 688-695. 
25. Dobbelaere, S.; Croonenborghs, A.; Thys, A.; Ptacek, D.; Vanderleyden, J.; Dutto, P.; Labandera-Gonzalez, C.; Caballero-Mellado, J.; Aguirre, J.F.; Kapulnik, Y. Responses of agronomically important crops to inoculation with Azospirillum Funct. Plant. Biol. 2001, 28, 871-879.

26. Jones, J.B. Hydroponics: A Practical Guide for the Soilless Grower, 2nd ed.; CRC Press: Boca Raton, FL, USA, 2005; Volume 1.

27. Olsen, C. The significance of concentration for the rate of ion absorption by higher plants in water culture. Physiol. Plant. 1950, 3, 152-164.

28. Bashan, Y.; Singh, M.; Levanony, H. Contribution of Azospirillum brasilense cd to growth of tomato seedlings is not through nitrogen fixation. J. Bot. 1989, 67, 2429-2434.

29. Gholami, A.; Shahsavani, S.; Nezarat, S. The effect of plant growth promoting rhizobacteria (PGPR) on germination, seedling growth and yield of maize. World Acad. Sci. Engineer. Technol. 2009, 37, 2070-3740.

30. Dobbelaere, S.; Croonenborghs, A.; Thys, A.; Ptacek, D.; Okon, Y.; Vanderleyden, J. Effect of inoculation with wild type Azospirillum brasilense and A. Irakense strains on development and nitrogen uptake of spring wheat and grain maize. Biol. Fertility Soils 2002, 36, 284-297.

31. Hadas, R.; Okon, Y. Effect of Azospirillum brasilense inoculation on root morphology and respiration in tomato seedlings. Biol. Fert. Soil. 1987, 5, 241-247.

32. El-Katatny, M.H. Enzyme production and nitrogen fixation by free, immobilized and coimmobilized inoculants of Trichoderma harzianum and Azospirillum brasilense and their possible mole in growth promotion of tomato. Food Technol. Biotechnol. 2010, 48, 161-174.

33. Vikram, A.; Hamzehzarghani, H.; Alagawadi, A.R.; Krishnaraj, P.U.; Chandrashekar, B.S. Production of plant growth promoting substances by phosphate solubilizing bacteria isolated from vertisols. J. Plant. Sci. 2007, 2, 326-333.

34. Khalid, A.; Arshad, M.; Zahir, Z.A. Screening plant growth-promoting rhizobacteria for improving growth and yield of wheat. J. Appl. Microbiol. 2004, 96, 473-480.

35. Miransari, M. Plant growth promoting rhizobacteria. J. Plant Nutr. 2014, 37, 2227-2235.

36. Saubidet, M.I.; Fatta, N.; Barneix, A.J. The effect of inoculation with Azospirillum brasilense on growth and nitrogen utilization by wheat plants. Plant Soil 2002, 245, 215-222.

37. Fages, J. Azospirillum inoculants and field experiments. In Azospirillum-Plant Associations; Okon, Y., Ed.; CRC Press: Boca Raton, FL, USA, 1994; pp. 87-109.

38. Zargari, K.; Khorshidi, Y.R.; Ardakani, M.R. Growth stimulant bacteria and nitrogen fertilizer effects plant nutrient uptake in rice (Oryza sativa 1). Int. J. Biosci. 2014, 4, 218-226.

39. Savitsky, P.; Gazaryan, I.; Tishkov, V.; Lagrimini, L.; Ruzgas, T.; Gorton, L. Oxidation of indole-3-acetic acid by dioxygen catalysed by plant peroxidases: Specificity for the enzyme structure. Biochem. J. 1999, 340, 579-583. 
40. Pereyra, C.M.; Ramella, N.A.; Pereyra, M.A.; Barassi, C.A.; Creus, C.M. Changes in cucumber hypocotyl cell wall dynamics caused by Azospirillum brasilense inoculation. Plant Physiol. Biochem. 2010, 48, 62-69.

(C) 2015 by the authors; licensee MDPI, Basel, Switzerland. This article is an open access article distributed under the terms and conditions of the Creative Commons Attribution license (http://creativecommons.org/licenses/by/4.0/). 